\title{
Expression of signal transducing G proteins in human melanoma cell lines
}

\author{
Eun-So Lee, ${ }^{1}$ Won Hyoung Kang, ${ }^{1}$ \\ Yoon-Hi Jin ${ }^{2}$ and Yong-Sung Juhnn ${ }^{2,3}$ \\ 1 Department of Dermatology, Ajou University School of Medicine, \\ Suwon 442-749, Korea \\ 2 Department of Biochemistry, Seoul National University College of \\ Medicine, Seoul 110-799, Korea \\ 3 Corresponding author \\ Accepted 13 November 1997
}

Abbreviations: $G$ protein, guanine nucleotide-binding regulatory protein; $G_{s}$, adenylyl cyclase stimulatory $G$ protein; $G_{s} \alpha, \alpha$ subunit of $G_{s} ; G_{i}$, adenylyl cyclase inhibitory $G$ protein; $\mathrm{G} \beta, \beta$ subunit of $\mathrm{G}$ protein; $\alpha$-MSH, $\alpha$-melanocyte-stimulating hormone; MAP kinase, mitogen activated protein kinase; $\mathrm{BE}$, brain equivalent

\begin{abstract}
Some malignant melanoma cells regress spontaneously by terminal differentiation, and understanding the mechanisms of this spontaneous regression can contribute to the development of a new therapy not only for melanoma but also for other cancers. The signal transducing $\mathrm{G}$ protein is one component of the signaling pathways for the differentiationinducing molecules such as $\alpha$-melanocyte-stimulating hormone ( $\alpha-\mathrm{MSH})$ and cAMP. To investigate the role of $G$ proteins in the differentiation process, we analyzed the expression of various $G$ proteins by quantitative Western blot and CAMP response in human malignant melanoma cell lines. SK-MEL-3 cells expressed the largest amount of stimulatory $\mathbf{G}$ protein alpha subunit $\left(G_{\mathbf{s}} \alpha\right)$ and the largest amount of inhibitory $G$ protein alpha subunit $\left(G_{j} \alpha\right)$ was expressed in Malme-3M cells among the 4 melanoma cell lines analyzed in this experiment. The SK-MEL28 cells exhibited largest amount of alpha subunit of $\mathrm{G}_{\mathrm{q}}$ and the beta subunits. The cAMP formation by forskolin stimulation was largest in the Malme-3M. The amount of CAMP forma-tion did not show any correlation with the expression of $\mathrm{G}_{\mathrm{s}} \alpha$ nor that of $\mathrm{G}_{i} \alpha$. The population doubling time was longest in Malme-3M cells. In this experiment, we found that the melanoma cells vary widely both in the expression of various $G$ proteins and in CAMP production depending on the cell lines.
\end{abstract}

Keywords: $\mathrm{G}$ proteins, melanocyte stimulating

\section{hormone $(\alpha-\mathrm{MSH})$, melanoma, cAMP, forskolin Introduction}

Malignant melanoma originates from melanocytes in the basal layer of epidermis, and its incidence is increasing dramatically in the United States and northern Europe (Herlyn, 1993). Very high fatality results from this cancer unless it is diagnosed and treated by excision at an early stage. In rare cases, however, malignant melanoma regresses spontaneously by terminal differentiation of the cancer cells. Such spontaneous terminal differentiation can be often induced by treatment with dibutyryl cAMP, a membrane permeable cAMP analog (Giuffre et al., 1988), and by treatment with $\alpha-M S H$ (Sukhanov et al., 1993). Understanding the mechanism of this spontaneous regression of melanoma can contribute to the development of a new therapy not only for melanoma but also for other cancers.

The differentiation-inducing $\alpha$-MSH binds to its specific receptor located at the external surface of melanocytes and melanoma cells, and the activated receptor activates stimulatory GTP-binding proteins $\left(\mathrm{G}_{\mathrm{S}}\right)$, which in turn stimulates adenylate cyclase to produce cAMP. The cAMP, as a second messenger, activates cAMP-dependent protein kinase (PKA), which in turn phosphorylates serine or threonine residue in many target proteins including those involved in growth and differentiation of melanoma cells.

Heterotrimeric signal transducing G proteins, including $\mathrm{G}_{\mathrm{s}}$, transduce extracellular signals into intracellular response by coupling receptors and effectors (Gilman, 1987). The $G$ protein is activated by binding with GTP and inactivated by hydrolysis of the bound GTP by its intrinsic GTPase activity. The activated $G$ proteins regulate intracellular effectors such as ion channels and enzymes including adenylate cyclase and phospholipase $C$ (Bourne et al., 1991). The G protein signaling system usually results in immediate responses such as activation of glycogen phosphorylase to breakdown glycogen, but it also induces long term effects such as regulation of cell proliferation and differentiation (Chen and lyengar, 1995). The $\mathrm{G}$ proteins regulate cell proliferation by modifying various protein kinases including mitogen activated protein kinases (Burgering et al., 1993). Both the alpha subunit and beta-gamma subunit complex of the $G$ protein are involved in the regulation of MAP kinase activities (Crespo et al., 1994), suggesting there are multiple crossover points between MAP kinase and G protein pathways (Faure et al., 1994).

It is obvious, therefore, that the $\mathrm{G}$ proteins are involved in the signaling pathways inducing the terminal differentiation of melanoma, but the role of $\mathrm{G}$ proteins in the 
differentiation process is not clear. Thus, we analyzed, in this experiment, the expression of various $\mathrm{G}$ proteins in human malignant melanoma cell lines by quantitative Western blot and cAMP response to investigate their roles in terminal differentiation.

\section{Methods and Materials}

\section{Cell culture}

Human malignant melanoma cell lines SK-MEL-2, SKMEL-3, SK-MEL-28, and Malme-3M were obtained from Korean Cell Line Bank of Seoul National Unversity, College of Medicine. Melanoma cells were grown in RPMI 1640 medium containing 10\% fetal bovine serum and incubated in a $\mathrm{CO}_{2}$ incubator at $37^{\circ} \mathrm{C}$.

\section{Measurement of population doubling time of melanoma cells}

A series of cultures at three different cell concentrations was set up using 24-well culture plates. The number of cells at regular intervals was counted with a hemocytometer until the cells reached plateau. The population doubling time was determined by plotting cell density on a log scale against time on a linear scale (Freshney, 1994).

\section{SDS-PAGE and Western blot analysis}

Confluent melanoma cells were harvested with a cell scraper, and the cells were resuspended in $10 \mathrm{vol}$. of a homogenization buffer composed of $50 \mathrm{mM}$ sodium phosphate, $\mathrm{pH} 7.4,1 \mathrm{mM}$ phenylmethylsulfonyl fluoride, $1 \mathrm{mM}$ EDTA, $10 \mu \mathrm{g} / \mathrm{ml}$ leupeptin, $1 \mu \mathrm{g} / \mathrm{ml}$ aprotinin, and 1 $\mathrm{mM}$ dithiothreitol. The cells were homogenized by passing through a 25 gauge needle 15 times on ice. The protein content was determined by the Lowry method, and the protein concentration of each sample was adjusted to 1 $\mathrm{mg} / \mathrm{ml}$ with the homogenization buffer.

Ten to $100 \mu \mathrm{g}$ of the homogenate protein was separated on a $12.5 \%$ SDS polyacrylamide gel and was transferred to nitrocellulose paper as described previously (Shin et al., 1995). The blot was blocked with $5 \%$ non-fat milk in phosphate buffered saline (PBS) for $1 \mathrm{~h}$, and then incubated at room temperature with an antibody against each G protein ( 1 to $5 \mu \mathrm{g} / \mathrm{ml}$ ) overnight. The nitrocellulose paper was then washed with $0.1 \%$ Tween 20 in PBS and incubated with peroxidase-labeled goat anti-rabbit IgG antibody (1:5000 dilution, Pierce, IL, USA) for $2 \mathrm{~h}$ at room temperature. The blot was washed with PBS and then incubated with enhanced chemiluminescence (ECL) substrate mixture (Amersham International, England) for $1 \mathrm{~min}$, and then exposed to an X-ray film (AGFA Curix RPI) for 1-5 min to obtain an image.

The density of each $\mathrm{G}$ protein band of the autoradiogram was quantified using a densitometer (Model GS-
700 , BioRad, USA), and the relative amount was calculated by comparing the density with the standard curve prepared with the brain cholate extract analyzed simultaneously in the same blot. The amount of the G protein was arbitrarily expressed as the brain equivalents (BE), and $1 \mu \mathrm{g} \mathrm{BE}$ is the amount of $G$ protein contained in $1 \mu \mathrm{g}$ of rat brain extract used as the reference standard. The brain extract was prepared by extracting rat whole brains with $1 \%$ cholate.

\section{Preparation of antibodies against $\mathrm{G}$ proteins}

The antibody against each $G$ protein was generated by immunizing rabbits with a peptide specific for each $G$ protein and purified by affinity chromatography on a column of Affi-Gel $15 \mathrm{gel}$ to which corresponding antigenic peptide had been coupled according to the manufacturer's manual (BioRad). The RM antibody was raised against the carboxyl terminal decapeptides of $\mathrm{G}_{\mathrm{s}} \alpha$, and it crossreacted with $G_{\text {olf }} \alpha$ which differs in only one amino acid residue from the $G_{s} \alpha$ peptides. The AS antibody was generated against carboxyl decapeptides of the peptides of transducin, and it reacted not only with the $\alpha$ subunit of transducin but also with the $\mathrm{G}_{\mathrm{i}} 1 \alpha$ and $\mathrm{G}_{\mathrm{i}} 2 \alpha$ which differs in a single amino acid residue from the $\alpha$ subunit of transducin. The QL antibody was generated against the carboxyl decapeptides of the $\alpha$ subunit of $G_{q}$, and it detected both $G_{q} \alpha$ and $G_{11} \alpha$. $G O$ was directed against carboxyl decapeptides of the $\alpha$ subunit of $G_{0}$. The SW antibody was generated against carboxyl decapeptides of beta subunit and it reacted with $\mathrm{G} \beta 1, \mathrm{G} \beta 2, \mathrm{G} \beta 3, \mathrm{G} \beta 4$, and $G \beta 5$.

\section{Measurement of cAMP formation}

Melanoma cells were plated into 24-well plates, and were allowed to grow overnight to become confluent. The cells were washed twice with phosphate buffered saline, and then treated for $30 \mathrm{~min}$ at room temperature with $10 \mu \mathrm{M}$ $\alpha-\mathrm{MSH}$ or $50 \mu \mathrm{M}$ forskolin in $500 \mu \mathrm{l}$ serum-free RPMI medium containing $0.1 \mathrm{mM}$ 3-isobutyl-1-methylxanthine (IBMX). The control cells were treated with the medium containing IBMX only. After washing the cells with PBS, cAMP was extracted with $500 \mu \mathrm{l}$ of $0.42 \mathrm{M}$ perchloric acid by incubating at $4^{\circ} \mathrm{C}$ for $30 \mathrm{~min}$. The perchloric acid extract was neutralized with $4.2 \mathrm{M}$ potassium hydroxide, and then CAMP was quantitated in duplicates with a CAMP assay system (Amersham International) that used cAMP binding proteins. The cAMP content was normalized by the protein content after measuring protein content of the melanoma cells by Lowry method.

The Kruskal-Wallis test and the Mann-Whitney $U$ test were performed to compare the cAMP formation in the melanoma cells.

\section{Results}

Melanoma cell lines expressed varying amounts of the 
G proteins. Stimulatory $G$ protein alpha subunit $\left(G_{s} \alpha\right)$ was detected as two bands each of which corresponded to $42 \mathrm{kDa}$ and $47 \mathrm{kDa}$ in all the melanoma cells analyzed in this experiment (Figure 1). There were more $42 \mathrm{kDa}$ $\mathrm{G}_{\mathrm{s}} \alpha$ present than $47 \mathrm{kDa} \mathrm{G}_{\mathrm{s}} \alpha$ in all the melanoma cell lines, although the relative ratios of the two forms differed. SK-MEL-3 cells expressed the largest amount of $\mathrm{G}_{\mathrm{s}} \alpha(3,171 \pm 686 \mu \mathrm{g} \mathrm{BE} / \mathrm{mg}$ proteins), while SK-MEL2 expressed the smallest amount, $584 \pm 124 \mu \mathrm{g} \mathrm{BE} / \mathrm{mg}$ proteins which was about $20 \%$ of the largest (Figure 2 ).

Inhibitory $G$ protein alpha subunit $\left(\mathrm{G}_{i} \alpha\right)$ was expressed in the largest amount in Malme-3M cells $(668 \pm 184 \mu \mathrm{g}$ $\mathrm{BE} / \mathrm{mg}$ proteins), while SK-MEL-2 expressed the smallest amount among the cell lines ( $209 \pm 22 \mu \mathrm{g} \mathrm{BE} / \mathrm{mg}$ proteins) which was about $30 \%$ of the largest (Figure 3 ). The expressions of $G_{s} \alpha$ and $G_{j} \alpha$ did not show any significant correlation in the melanoma cell lines.

The alpha subunit of $G_{q}$ was expressed at the highest level in SK-MEL-28 (107 $\pm 18 \mu \mathrm{g} \mathrm{BE} / \mathrm{mg}$ proteins), which also expressed the highest amount of the beta subunits (258 $\pm 52 \mu \mathrm{g} \mathrm{BE} / \mathrm{mg}$ proteins) (Figure 3). The melanoma cell lines exhibited less variable amounts of $G_{q} \alpha$ and $G \beta$ than $\mathrm{G}_{\mathrm{s}} \alpha$. The alpha subunit of $\mathrm{G}_{\mathrm{o}}$ was not detected enough to allow quantitative analysis by Western blot.

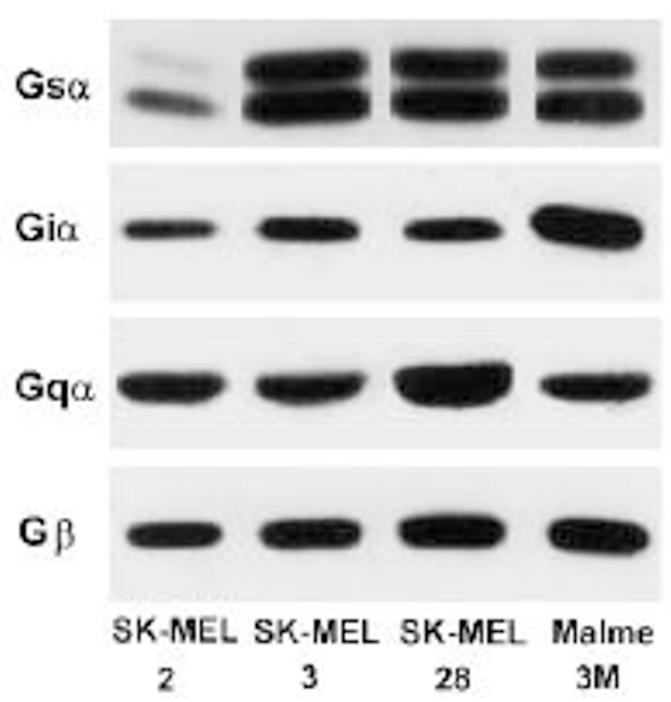

Figure 1. Representative immunoblots of the $G$ proteins in human melanoma cell lines. Ten to $100 \mu \mathrm{g}$ of proteins from melanoma cell homogenates was separated by $12.5 \%$ SDS-PAGE and transferred onto nitrocellulose paper. The blot was incubated with RM, AS, QL, and SW antibody directed against $\mathrm{G}_{s} \alpha, \mathrm{G}_{\mathrm{j}} \alpha, \mathrm{G}_{q} \alpha$ and $\mathrm{G} \beta$, respectively, and then with peroxidase labeled goat anti-rabbit lg $G$ antibody. The $G$ protein was visualized by incubating the blot with $\mathrm{ECL}$ reagent followed by exposure to an X-ray film.
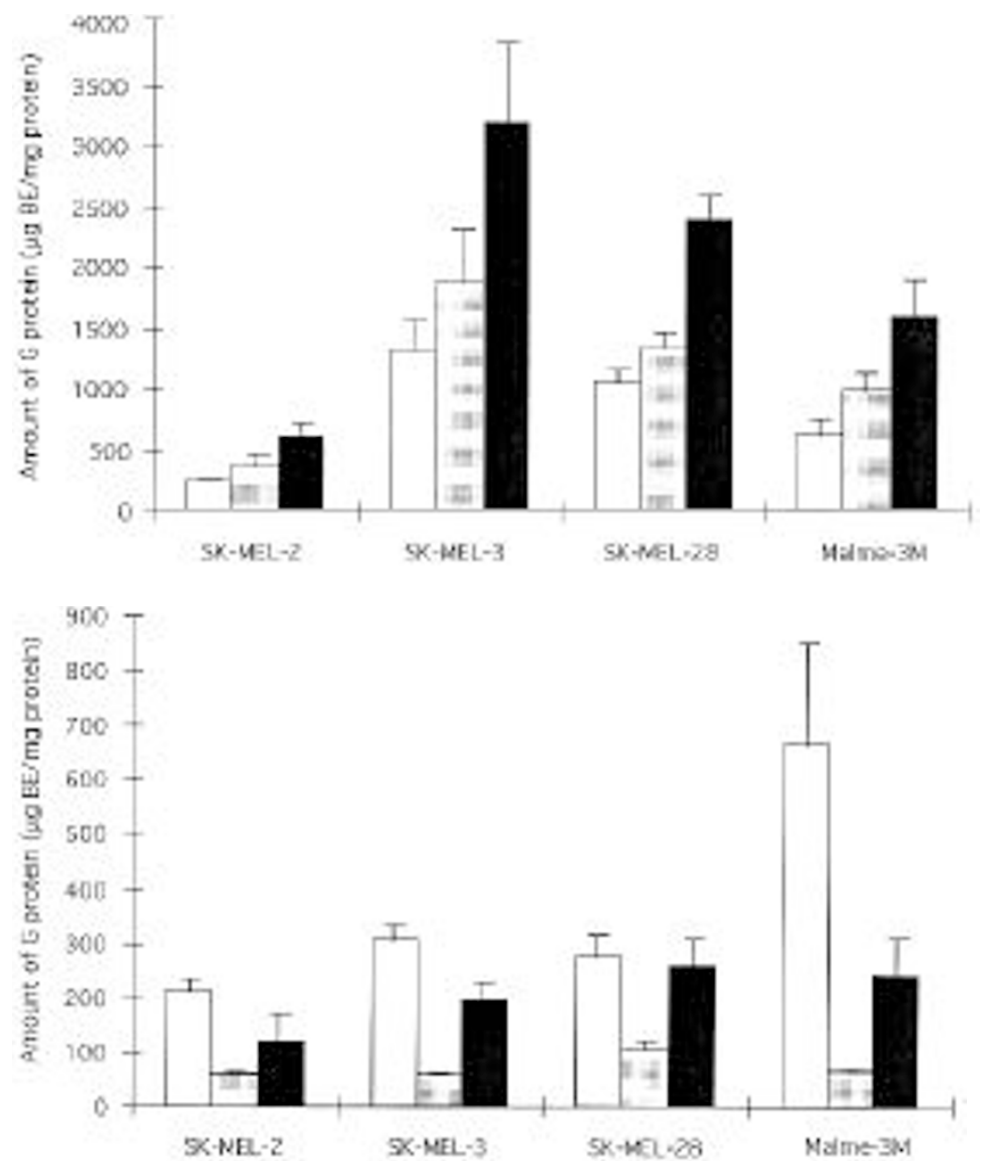

Figure 2. The expression of $\mathrm{G}_{\mathrm{s}} \alpha$ proteins in human melanoma cell lines. Expression of $\mathrm{G}$ proteins was analyzed by immunoblot as described in the legend of Figure 1, and the concentration of $G$ proteins was determined by measuring the density of the $G$ protein bands in the autoradiogram. The amount of the $G$ protein was arbitrarily expressed as the brain equivalents $(\mathrm{BE})$ per $\mathrm{mg}$ proteins, and the values of mean \pm standard deviation of 5 samples analyzed in duplicates were plotted. Empty column, $43 \mathrm{kDa} \mathrm{Gs} \alpha$; dotted column, $47 \mathrm{kDa} \mathrm{G}_{s} \alpha$; filled column, total $\mathrm{G}_{s} \alpha$.
Figure 3. The expression of $\mathrm{G}_{i} \alpha, \mathrm{G}_{q} \alpha$, and $\mathrm{G} \beta$ proteins in human melanoma cell lines. Empty column, $\mathrm{G}_{j} \alpha$; dotted column, $\mathrm{G}_{q} \alpha$; filled column, G $\beta$. See the legend of Figure 2. 


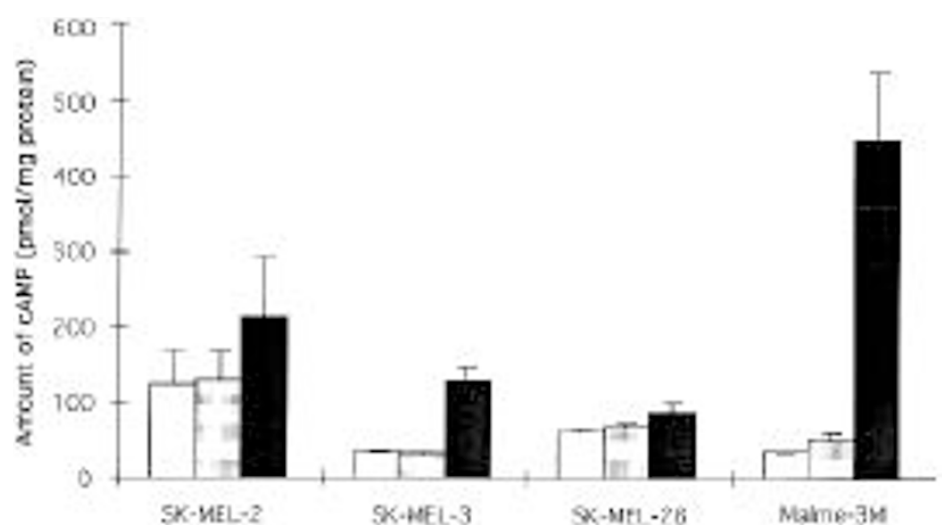

Figure 4. Formation of cAMP in melanoma cells stimulated with $\alpha$ MSH and forskolin. Melanoma cells were plated into 24-well plates, and treated with serum-free RPMI medium containing $10 \mu \mathrm{M} \alpha$ $\mathrm{MSH}$ (dotted column) or $50 \mu \mathrm{M}$ forskolin (filled column) for 30 minutes at room temperature. The control (empty column) cells were treated with the medium containing IBMX only. CAMP was extracted with perchloric acid, and quantitated in duplicates using a CAMP assay kit. cAMP content was normalized by the protein content. The mean \pm SDof 4 samples analyzed in duplicates were plotted.
The cAMP formation by stimulation with forskolin was largest in the Malme-3M (449 $\pm 91 \mathrm{pmol} / \mathrm{mg}$-protein), with the least amount in the SK-MEL-28 cells $(88 \pm 11$ $\mathrm{pmol} / \mathrm{mg}$-protein) (Figure 4). Stimulation with $\alpha-\mathrm{MSH}$ increased cAMP formation significantly in Malme-3M cells only (from control, $34.72 \pm 2.23 \mathrm{pmol} / \mathrm{mg}$-protein to $51.71 \pm 9.43, P<0.05$ ), and no significant increase was observed in other melanoma cells. The amount of cAMP formation did not show any positive correlation with the expression of $G_{s} \alpha$ nor inverse relationship with the expression of $G_{i} \alpha$.

The population doubling time of melanoma cell lines was longest with Malme-3M $(23.1 \pm 5.3 \mathrm{~h})$, and shortest with SK-MEL-3 and SK-MEL-28 $(17.4 \pm 4.4 \mathrm{~h}, 17.5 \pm 5.6$ $h$, respectively) (Table 1). Malme-3M exhibited greatest forskolin-stimulated cAMP production, and SK-MEL-3 and SK-MEL-28 exhibited least CAMP response to forskolin treatment. The doubling time did not exhibit any correlation with the expression of any of the $\mathrm{G}$ proteins.

\section{Discussion}

In this study, we found that the melanoma cells vary widely both in the expression of various $G$ proteins and in cAMP production depending on the cell lines. This result indicates that the activity of CAMP signaling pathway is quite different from one melanoma cell line to another, which suggests that each melanoma cell line may exhibit different responses including cell proliferation and differentiation to the activation of cAMP pathways.

The $\mathrm{G}_{\mathrm{s}} \alpha$ stimulates adenylate cyclase to increase cAMP concentration when various signals including $\alpha-\mathrm{MSH}$ activate their receptors, and we found in this experiment that the expression of $\mathrm{G}_{\mathrm{s}} \alpha$ varied widely among the melanoma cell lines analyzed. However, the expression of $\mathrm{G}$ proteins was not correlated with cAMP production followed by stimulation with either $\alpha-M S H$ or forskolin. The cAMP production independent to $\mathrm{G}_{\mathrm{s}} \alpha$ by $\alpha-\mathrm{MSH}$ might reflect the stoichiometry of the cAMP signaling
Table 1. The population doubling time of melanoma cells. A series of cultures at three different cell concentrations was set up using 24-well culture plates. The cells were counted at regular intervals with a hemocytometer, and the doubling time was determined by plotting cell density against time on a semi-log scale paper. The doubling time was expressed as average $\pm S D$, where $n$ represented the number of analysis.

\begin{tabular}{cc}
\hline Cell lines & Doubling time $(h)$ \\
\hline SK-MEL-2 $(n=15)$ & $19.7 \pm 6.5$ \\
SK-MEL-3 $(n=11)$ & $17.4 \pm 4.4$ \\
SK-MEL-28 $(n=14)$ & $17.5 \pm 5.6$ \\
Malme-3M $(n=9)$ & $23.1 \pm 5.3$ \\
\hline
\end{tabular}

pathway, because $\mathrm{G}_{\mathrm{s}} \alpha$ was reported to be expressed 12.5-fold more copies per cell than IP prostanoid receptor in NG108-15 cells (Kim et al., 1994). Treatment with $\alpha$ MSH resulted in a small increase of cAMP concentration only in Malme-3M cells. This result may reflect the amount of $\alpha$-MSH-specific receptor on the cell membranes, because melanoma cells express receptors for $\alpha-\mathrm{MSH}$ in variable abundance (Eberle et al., 1993). Since this expression of $\alpha-\mathrm{MSH}$ receptors is reported to be regulated by many factors including CAMP-dependent protein kinase, the activity of cAMP pathway might regulate the expression of the $\alpha-\mathrm{MSH}$ receptor (Siegrist et al., 1994).

Forskolin activates adenylate cyclase without involvement of G proteins, and the increase of cAMP concentration by its treatment reflects the activity of adenylyl cyclase. This study shows that the expression of $G$ protein and adenylate cyclase activity are not correlated in melanoma cells. However, the increase in cAMP formation by forskolin treatment exhibited coincidental patterns to the cell doubling times of melanoma cells. Malme-3M melanoma cells exhibited highest increase in cAMP formation, and it had the longest doubling time. SK-MEL-3 and SK-MEL28 showed the least cAMP response and the shortest doubling times. These results suggest that melanoma cells with a higher cAMP response may grow slowly resulting in a longer cell doubling time. This hypothesis 
can be supported by the fact that cAMP can induce differentiation of melanoma cells (Giuffre et al., 1988), but needs further evaluations.

The concentration of intracellular cAMP is regulated not only by adenylate cyclase but also by CAMP phosphodiesterases that hydrolyze cAMP into 5' AMP (Beavo, 1995). Besides, the adenylate cyclase has at least 9 isoforms (Sunahara et al., 1996), and the phosphodiesterase activity has been reported in more than 30 enzymes, the isoforms of which show different responses to the regulating molecules. Thus more information on the expression and the regulatory properties of the isoforms of the two enzymes are essential for better understanding of the cAMP signaling pathway of melanoma cells (Houslay and Milligan, 1997). Such knowledge will contribute to clarifying the mechanisms of terminal differentiation of melanoma cells induced by CAMP analogs and cAMPincreasing agents such as forskolin.

Along with cAMP signaling pathway, many other $\mathrm{G}$ protein coupled signaling pathways, including inositol phosphate pathway, regulate cell growth and proliferation. Our finding that melanoma cells also express other $G$ proteins such as $\mathrm{G}_{\mathrm{i}}, \mathrm{G}_{\mathrm{q}}$, and $\mathrm{G} \beta$ in quite different amounts depending on the cell lines implies that each melanoma cell line has its own intracellular signaling environment that determines many cellular characteristics including growth and proliferation.

In summary, this experiment was performed as an initial step toward elucidating the role of $G$ proteins in terminal differentiation, and we found that the melanoma cells vary widely both in the expression of various $G$ proteins and in CAMP production stimulated with either $\alpha-\mathrm{MSH}$ or forskolin depending on the cell lines.

\section{Acknowledgement}

This research was supported by NON DIRECTED RESEARCH FUND (1994) from Korea Research Foundation.

\section{References}

Beavo, J. A. (1995) Cyclic nucleotide phosphodiesterases: functional implications of multiple isoforms. Physiol. Rev. 75: 725-748

Bourne, H. R., Sanders, D. A. and McCormick, F. (1991) The GTPase superfamily: conserved structure and molecular mechanism. Nature 349: 117-127
Burgering, B. M., Pronk, G. J., van Weeren, P. C., Chardin, P. and Bos, J. L. (1993) CAMP antagonizes p21ras-directed activation of extracellular signal-regulated kinase 2 and phosphorylation of mSos nucleotide exchange factor. EMBOJ. 12: 4211-4220

Chen, J. and lyengar, R. (1995) Interactions between the $G_{s} /$ protein kinase $A$ and the Ras/MAP-kinase signalling pathways. Biochem. Soc. Trans. 23: 129-133

Eberle, A. N., Siegrist, W., Bagutti, C., Chluba-De Tapia, J., Solca, F., Wikberg, J. E. and Chhajlani, V. (1993) Receptors for melanocyte-stimulating hormone on melanoma cells. Ann. NY Acad. Sci. 680: 320-341

Faure, M., Voyno Yasenetskaya, T. A. and Bourne, H. R. (1994) cAMP and beta gamma subunits of heterotrimeric $G$ proteins stimulate the mitogen-activated protein kinase pathway in COS-7 cells. J. Biol. Chem. 269: 7851-7854

Freshney RI (1994). Quantitation and Experimental Design. In Culture of Animal Cells. A Mannual of Basic Technique, pp. 267-286, Wiley-Liss, Inc., New York

Gilman, A. G. (1987) G-proteins: transducers of receptor-generated signals. Annu. Rev. Biochem. 56: 615-649

Giuffre, L., Schreyer, M., Mach, J. P. and Carrel, S. (1988) Cyclic AMP induces differentiation in vitro of human melanoma cells. Cancer $61: 1132-1141$

Herlyn, M. (1993). Molecular and Celluar Biology of Melanoma. R. G. Randes Company, Austin

Houslay, M. and Milligan, G. (1997) Tailoring cAMP-signalling responses through isoform multiplicity. Trends Biochem. Sci. 22: 217-224

Kim, G. D., Adie, E. J. and Milligan, G. (1994) Quantitative stoichiometry of the proteins of the stimulatory arm of the adenylyl cyclase cascade in neuroblastoma $\times$ glioma hybrid, NG108-15 cells. Eur. J. Biochem. 219: 135-43

Shin, C. J., Kim, Y. S., Park, J. B. and Juhnn, Y. S. (1995) Changes in G protein levels in the hippocampus and the striatum of rat brain after chronic treatment with haloperidol and sulpiride. Neuropharmacology 34: 1335-1338

Siegrist, W., Stutz, S. and Eberle, A. N. (1994) Homologous and hetero-logous regulation of alpha-melanocyte-stimulating hormone receptors in human and mouse melanoma cell lines. Cancer Res. 54: 2604-10

Sukhanov, V. A., Voronkova, I. M., Shvets, S. V. and Morozova, L. F. (1993) Melanocyte stimulating hormone inhibits growth of amelanotic cells of human malignant melanoma with concomitant changes in concentration of CAMP, phosphtidylinositols, and inositol phosphates. Biokhimiya 58: 221-223

Sunahara RK, Dessauer CW and Gilman AG. (1996) Complexity and diversity of mammalian adenylyl cyclases. Annu. Rev. Pharmacol. Toxicol. 36: 461-80 